\title{
Response to bronchodilators assessed by lung mechanics
}

\author{
A GREENOUGH, B G LOFTUS, J POOL, AND J F PRICE \\ Department of Child Health, King's College Hospital, London
}

SUMMARY Abnormalities of compliance and functional residual capacity were shown in eight young children aged 2-8 years with asthma during an acute attack. In a randomised, placebo controlled study treatment with bronchodilator (salbutamol) was associated with a significant improvement in compliance and lessening of hyperinflation as shown by a reduction in functional residual capacity.

Asthma is a common illness in young children. ${ }^{1}$ Unfortunately, the response to treatment with bronchodilator in such patients is considered to be small and less predictable than in older children and adults. ${ }^{2}$ Knowledge regarding the response to treatment remains limited because of the difficulties in obtaining objective measurements of lung function at this age. Previous studies that have attempted to assess the effectiveness of such treatment with bronchodilators in young children have used a modification of the forced oscillation technique for determination of resistance. ${ }^{3}$ This technique relies on the assumption that the respiratory system functions as a single unit, which may not be valid in a disease such as asthma that can cause nonuniform, asymmetrical changes. Also as the respiratory system can be affected by such problems as upper respiratory tract infections, common in young children, it cannot be universally applied.

Despite these limitations, Groggins et al have been able to show changes in resistance in response to oral theophylline and salbutamol ${ }^{4}$ and nebulised ipratropium bromide and salbutamol but not clemastine $^{5}$ in young children. The same group, however, were unable to show either reduction in resistance measured by the forced oscillation method or a fall in thoracic gas volume measured plethysmographically after treatment with nebulised salbutamol in wheezing children less than 18 months of age, and suggested this as an age limit below which treatment with bronchodilators might not be effective. $^{6}$

Recently, we have been able to perform measurements of both functional residual capacity and compliance of the respiratory system reliably and accurately in children aged $2-7$ years. ${ }^{7}$ In a prelimin- ary study using these tests we showed significant abnormalities in both lung volume and compliance in children with severe and symptomatic asthma. In adults similar abnormalities can be reversed by appropriate treatment to relieve airways obstruction. ${ }^{8}$ This study investigated whether the combined techniques of measurement of compliance of the respiratory system and functional residual capacity could similarly be used in young children to document the response to treatment with bronchodilators.

\section{Patients and methods}

Study protocol. Eight children (six $<5$ years of age) admitted to our hospital with acute asthma were studied. The study group consisted of five boys and three girls aged $2 \cdot 1$ to $8 \cdot 0$ years, with a mean age of 4.9 years. The children were entered into the study as soon as intravenous treatment for status asthmaticus was stopped and they were able to tolerate regular treatment by nebuliser. Immediately before a scheduled inhalation of treatment with bronchodilator the child visited the respiratory laboratory. Functional residual capacity and compliance of the respiratory system were measured (see below). The child was then randomised to receive either saline $(3 \mathrm{ml})$ or salbutamol $(2.5 \mathrm{mg}$ if $<5$ years of age and $5 \mathrm{mg}$ if $>5$ years) in $3 \mathrm{ml}$ of saline through a nebuliser. Ten minutes later compliance of the respiratory system and functional residual capacity were again measured. Those children who had received salbutamol returned immediately to the ward and those who had received saline were given their scheduled dose of salbutamol before leaving the laboratory. This procedure was 
repeated at the time of the next scheduled treatment, the child receiving the alternative solution.

Lung function measurements. All measurements were performed with the child in a sitting position breathing into a water sealed spirometer (Gould Pulmonet 3) through a face mask.

First functional residual capacity was measured by helium gas dilution. Equilibration was assumed when there had been a change of less than $20 \mathrm{ml}$ in functional residual capacity over a 30 second period. Compliance of the respiratory system was then measured by weighted spirometry. After establishing a constant end expiratory level on the spirometric volume recording a $500 \mathrm{~g}$ brass weight was placed on the spirometer bell. This produced a constant positive pressure within the circuit of approximately $2 \mathrm{~cm} \mathrm{H}_{2} \mathrm{O}$ and increased the end expiratory level. Airway pressure was measured through a side port (Sanborn pressure transducer, model No $268 \mathrm{~B}$ ). The weight was removed after a new stable baseline had been achieved, the end expiratory level then returning to the previous baseline. This procedure was repeated five times during the study. Combined compliance of the respiratory system and spirometer circuit was calculated from the mean volume and pressure changes of the five weight applications. Compliance of the spirometer circuit alone had been previously calculated by applying a series of weights to the bell with the circuit closed, this was then subtracted from the total compliance to give compliance of the respiratory system. Volumes were all corrected to body temperature, pressure, and saturation conditions.

The measurements together take less than five minutes and are reproducible (a coefficient of variation of $<10 \%$ for repeated measurements both in healthy children ${ }^{7}$ and children with asthma).

All calculations of compliance of the respiratory system and functional residual capacity were performed by one of us (AG). Individual traces were coded so that this researcher was unaware of the patient's characteristics and the relation to the trial

Table Mean (range) changes in fractional residual capacity and compliance of the respiratory system in response to treatment with saline and salbutamol (expressed as percentage of predicted for height)

\begin{tabular}{clllll}
\hline & \multicolumn{2}{l}{ Saline } & & \multicolumn{2}{l}{ Salbutamol } \\
\cline { 2 - 3 } & Before & After & & Before & After \\
\hline $\begin{array}{c}\text { Functional residual } \\
\text { capacity }\end{array}$ & 133 & 134 & & 137 & 125 \\
$\begin{array}{c}\text { Compliance of the } \\
\text { respiratory system }\end{array}$ & $\begin{array}{c}(111-157) \\
72\end{array}$ & $\begin{array}{c}(119-147) \\
70\end{array}$ & $\begin{array}{c}(124-158) \\
71\end{array}$ & $\begin{array}{c}(111-145) \\
82\end{array}$ \\
& $(51-95)$ & $(47-95)$ & $(49-93)$ & $(56-103)$ \\
\hline
\end{tabular}

schedule. The results are expressed as a percentage of the predicted height and weight using our own data from 60 healthy children of a similar age group. ${ }^{7}$

In the three older children it was possible to make peak flow measurements in addition to measurements of compliance of the respiratory system and functional residual capacity.

Ethical permission. Ethical permission for this study was granted by King's College Hospital ethical committee, and parental consent was also obtained.

Statistical analysis. Changes in functional residual capacity and compliance of the respiratory system with salbutamol and placebo were compared and assessed for significance using the paired Student's $t$ test.

\section{Results}

All eight children had raised functional residual capacities and reduced compliance of the respiratory systems (Table) at the start of the study compared with our data for normal children for this age group. ${ }^{7}$ There was no significant difference between the baseline measurements, expressed as a percentage predicted for height of our data for normal children ${ }^{7}$ before administration of saline and salbutamol (Table). Administration of saline was

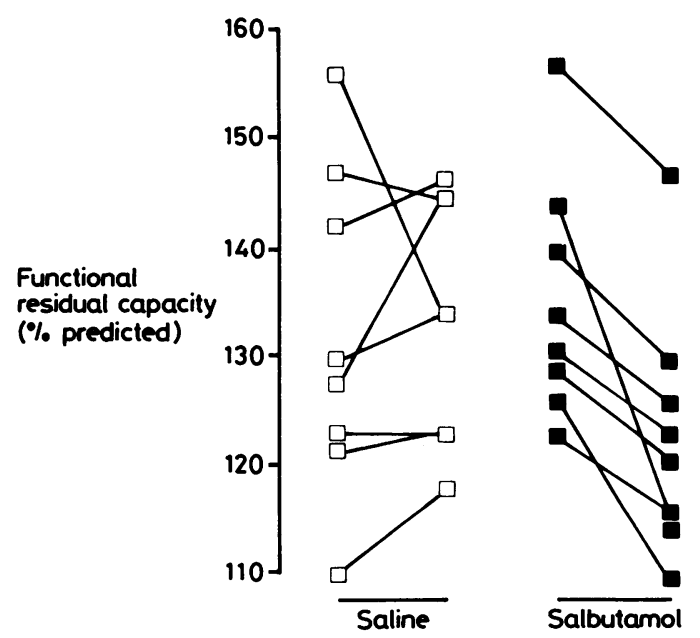

Fig. 1 Changes in functional residual capacity in response to administration of saline and salbutamol (results expressed as a percentage of the predicted normal value for height).

Individual children's responses to either saline or salbutamol are shown by linked data points. 


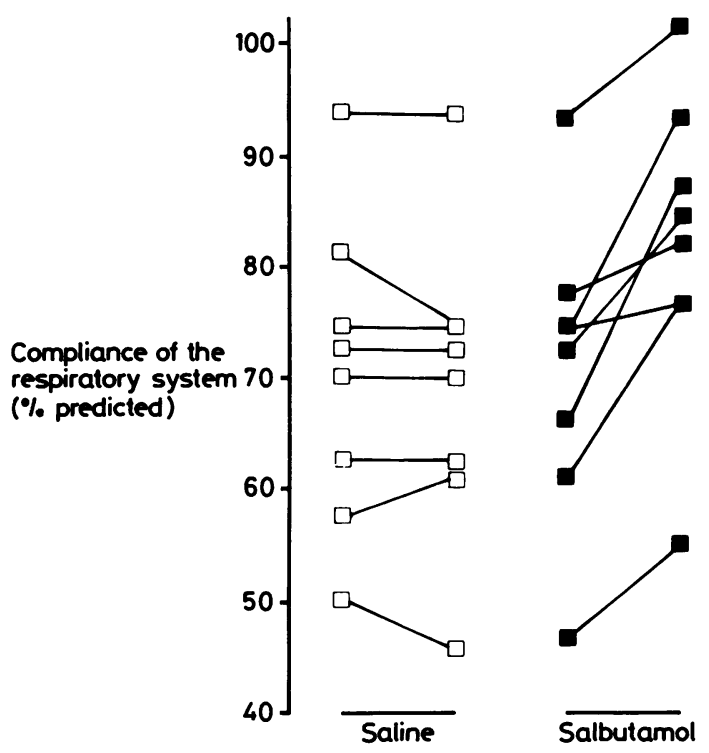

Fig. 2 Changes in compliance of the respiratory system in response to administration of saline and salbutamol (results expressed as a percentage of the predicted normal value for height). Individual children's responses to either saline or salbutamol are shown by linked data points.

associated with only a small variable change in both functional residual capacity (mean change $1 \cdot 1 \%$ ) and compliance of the respiratory system (mean change $2 \%$ ). All changes are expressed as the difference between measurements before and after nebulised treatment, both measurements expressed as the percentage predicted for height using our own data for normal children. ${ }^{7}$ Administration of salbutamol was associated with a consistent reduction in functional residual capacity, mean change $12.3 \%$ (Fig. 1), and a rise of compliance of the respiratory system, mean change $11.5 \%$ (Fig. 2$)(p<0.05)$.

Only three children were able to perform peak flow measurements reproducibly. Administration of saline was associated with a small but variable response (changes of $-7 \%, 0 \%$, and $+3 \%$ ), peak flow measurements being expressed as percentage predicted for height using the data for normal children of Lunn. ${ }^{9}$ Administration of salbutamol was associated with a consistent improvement in peak flow (changes of $15 \%, 13 \%$, and $20 \%$ ).

\section{Discussion}

Successful clinical management is essential to be able to diagnose accurately, describe the pattern and severity of the disease, and monitor the response to treatment. Chai et al assessed the value of methods of measurement commonly used in young children with asthma: clinical examination, history, pulmonary physiology, medication requirements, and school activity. ${ }^{10}$ Their conclusion was that physiological measurements of pulmonary function were very important and provided the only objective measurement available in the assessment of state of asthma. Traditionally, peak expiratory flow has been used to assess state of asthma, particularly the response to treatment. Its main recommendation is its simplicity, which means that the test can be performed repeatedly and at home. ${ }^{11}$ Peak expiratory flow, however, is influenced mainly by obstruction in the larger airways, thus large abnormalities of small airway flow, which occur in such children, may not be detected by peak flow measurements. ${ }^{12}$ In young children measurements of peak flow also may be unreliable because of limited patient cooperation.

In this study the combined measurements of compliance of the respiratory system and functional residual capacity were not only well tolerated but also showed abnormalities of compliance and lung volume. Rises in lung volume in older children have previously been documented by plethysmographic measurements both in severe chronic asthma ${ }^{11}$ and in response to antigen induced asthma. ${ }^{13}{ }^{14}$ In the present study these abnormalities of both compliance and lung volume were consistently reversed by treatment with bronchodilators but not with saline and confirm earlier reports from adults and older children. McIlroy and Marshall measured the mechanical properties of the lungs in patients with asthma at rest and during exercise and showed increased stiffness of the lungs, which was less pronounced after treatment with bronchodilators. ${ }^{15}$ Woolcock and Read found that lung volume may be raised as much as three to five litres above normal in acute asthma attacks and that this was reduced by appropriate treatment. ${ }^{16}$ Even among asymptomatic children (aged 8-13 years) Tooley et al found similar abnormalities, which again were reversed by treatment with bronchodilators. ${ }^{17}$ They went on to emphasise the importance of early detection and treatment of this abnormality to prevent possible permanent structural changes as a result of hyperinflation.

It is suggested from these preliminary results that this technique, combined measurement of compliance of the respiratory system and functional residual capacity, may be useful in assessing response to treatment in young children with asthma in whom peak flow measurements may not be possible. Further work is necessary to assess 
whether the magnitude of the response is related to the age of the child or the severity of their disease.

Financial support for this work was provided by Children Nationwide Medical Research Fund. We are grateful to Mrs Angela McPherson for secretarial help.

\section{References}

${ }^{1}$ Strachan DP. The prevalence and natural history of wheezing in early childhood. J $R$ Coll Gen Pract 1975;35:182-4.

2 Pearce JL, Wesley HMM. Children with asthma: will nebulised salbutamol reduce hospital admissions? $\mathrm{Br}$ Med J 1985;290: 595-7.

3 Cogswell JJ. Forced oscillation technique: a determination of resistance to breathing in children. Arch Dis Child 1973;48: 259-66.

${ }^{4}$ Groggins RC, Lenney W, Milner AD, Stokes GM. Efficacy of orally administered salbutamol and theophylline in preschool children with asthma. Arch Dis Child 1980;55:204-6.

${ }^{5}$ Groggins RC, Milner AD, Stokes GM. Bronchodilator effects of clemastine, ipratropium bromide and salbutamol in preschool children with asthma. Arch Dis Child 1981;56:342-4.

6 Lenney W, Milner AD. At what age do bronchodilators work? Arch Dis Child 1978;53:532-5.

${ }^{7}$ Greenough A, Stocks J, Nothen U, Helms P. Total respiratory compliance and functional residual capacity in young children. Pediatric Pulmonology. (In press.)
8 Woolcock AJ, Read J. Improvement in bronchial asthma not reflected in forced expiratory volume. Lancet 1965;ii:1323-5.

9 Lunn JE. Respiratcry measurements of 3,556 Sheffield school children. Preventative and Social Medicine 1965;19:115-22.

${ }^{10}$ Chai H, Purcell K, Brady K, Falliers CJ. Therapeutic and investigational evaluation of asthmatic children. Journal of Allergy 1968;41:23-37.

11 Steiner N, Phelan PD. Physiological assessment of severe chronic asthma in children. Respiration 1978;35:30-6.

12 Mead J, Turner JM, Macklem PT, Little JP. Significance of the relationship between lung recoil and maximum expiratory flow. J Appl Physiol 1967;22:95-108.

13 Mansell A, Dubrawsky C, Levison $\mathrm{H}$, et al. Lung mechanics in antigen-induced asthma. J Appl Physiol 1974;37:297-301.

14 Warner JO. Significance of late reactions of the bronchial challenge with house dust mite. Arch Dis Child 1976;51:905-11.

15 McIlroy MB, Marshall R. Mechanical properties of the lungs in asthma. Clin Sci 1956;15: 345-51.

16 Woolcock AJ, Read J. Lung volumes in exacerbations of asthma. Am J Med 1966;41:259-73.

17 Tooley WH, DeMuth G, Nadel JA. The reversibility of obstructive changes in severe childhood asthma. J Pediatr $1965 ; 66: 517-24$.

Correspondence to Dr A Greenough, Department of Child Health, King's College Hospital, Denmark Hill, London SE5 8RX.

Received 27 June 1986 